\title{
Effects of dihydrotestosterone on osteoblast activity in curdlan-administered SKG mice and osteoprogenitor cells in patients with ankylosing spondylitis
}

Sungsin Jo ${ }^{1 \dagger}$, Eun-Ju Lee ${ }^{2 \dagger}$, Bora $\mathrm{Nam}^{3}$, Juyeon Kang ${ }^{3}$, Seunghun Lee ${ }^{4}$, Jeehee Youn ${ }^{5}$, Ye-Soo Park ${ }^{6}$, Yong-Gil Kim ${ }^{2 *}$ and Tae-Hwan Kim ${ }^{1,3^{*}}$ (D)

\begin{abstract}
Background: Ankylosing spondylitis (AS) is characteristically male-predominant, and progressive spinal ankylosis affects male patients more severely; however, the hormonal effects in males with AS are poorly understood.

Methods: In the present study, the regulatory effects of dutasteride, a 5-a reductase inhibitor that blocks the conversion of testosterone to dihydrotestosterone (DHT), were examined in curdlan-administered male SKG mice to determine spinal bone formation, bone metabolism-related markers, and interleukin (IL)-17A cytokine and T cell populations. In addition, the effects of DHT on primary osteoprogenitors from the facet joints of AS patients were assessed based on osteoblast-related parameters. DHT level was measured, and the correlation with modified Stoke Ankylosing Spondylitis Spinal Score (mSASSS) was analyzed in AS patients.

Results: In curdlan-administered SKG mice, dutasteride treatment resulted in an increased accumulation of hydroxyapatite in the spine which was positively correlated with serum IL-17A levels. In the analysis of bone metabolism-related molecules, a decrease in sclerostin levels was observed in the sera in the dutasteride group. Continuous exposure to DHT resulted in fewer calcium deposits in AS osteoprogenitors during osteoblast differentiation. DHT-treated AS osteoprogenitors showed decreased osteocalcin and increased DKK1 and SOST1 mRNA expression, supporting the results of the in vivo experiments. Treatment with dutasteride upregulated bone formation in the spine of curdlan-administered SKG mice and DHT treatment downregulated osteoblast differentiation in vitro.

Conclusions: Treatment with dutasteride affected the bone formation in the spine of curdlan-treated SKG mice, and DHT treatment attenuated osteoblast differentiation in vitro. Therefore, contrary to what could be expected if osteoblasts contributed to spinal ankylosis, DHT inhibition might increase rather than decrease the progression of spinal ankylosis despite the higher levels of DHT observed in many AS patients.
\end{abstract}

Keywords: Ankylosing spondylitis, Spinal ankylosis, Dutasteride, Curdlan-administered SKG mice, Dihydrotestosterone, Osteoprogenitors, Osteoblastic activity

\footnotetext{
* Correspondence: bestmd2000@amc.seoul.kr; thkim@hanyang.ac.kr

† Sungsin Jo and Eun-Ju Lee contributed equally to this work.

${ }^{2}$ Division of Rheumatology, Department of Medicine, University of Ulsan

College of Medicine, Asan Medical Center, Seoul, Republic of Korea

${ }^{1}$ Hanyang University Institute for Rheumatology Research, Seoul, Republic of Korea

Full list of author information is available at the end of the article
}

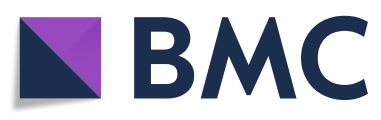

(c) The Author(s). 2020 Open Access This article is licensed under a Creative Commons Attribution 4.0 International License, which permits use, sharing, adaptation, distribution and reproduction in any medium or format, as long as you give appropriate credit to the original author(s) and the source, provide a link to the Creative Commons licence, and indicate if changes were made. The images or other third party material in this article are included in the article's Creative Commons licence, unless indicated otherwise in a credit line to the material. If material is not included in the article's Creative Commons licence and your intended use is not permitted by statutory regulation or exceeds the permitted use, you will need to obtain permission directly from the copyright holder. To view a copy of this licence, visit http://creativecommons.org/licenses/by/4.0/ The Creative Commons Public Domain Dedication waiver (http://creativecommons.org/publicdomain/zero/1.0/) applies to the data made available in this article, unless otherwise stated in a credit line to the data. 


\section{Background}

Ankylosing spondylitis (AS) is a male-predominant disease, and its symptomatic burden as well as the progression of spinal changes is more severe in male patients $[1,2]$. Male hormone analysis in AS patients has been reported [3-5]; however, an obvious difference in the effects of hormones was not observed. The putative effects of male hormones are difficult to ascertain because AS is a multifactorial disease. Syndesmophytes are the first indicator of spinal ankylosis in AS. The syndesmophyte formation is orchestrated by a variety of immune cells in response to multifaceted factors including genetic factors such as HLA-B27, chronic inflammation, and environmental factors with mechanical stress [6-8]. Furthermore, interleukin (IL)-17A levels and the number of IL-17A-secreting cells are higher in male AS patients [9]. Exogenous IL-17A treatment of primary bonedriven cells in AS patients promotes osteoblast activity and differentiation [10]; however, the association between male hormones and pathogenic subset of immune cells or syndesmophyte formation remains unknown.

SKG mice possess a mutation in the ZAP70 gene, a key signaling molecule in $\mathrm{T}$ cells [11]. Although SKG mice have been used as an animal model of rheumatoid arthritis (RA), curdlan-administered SKG mice showed spontaneous inflammatory arthritis and developed spinal bony fusion over time [12-14]. Therefore, the curdlanadministered SKG mice have been suggested as a model of human spondyloarthritis.

Testosterone affects immune responses such as differentiation and cytokine production of T cells, B cells, and macrophages. Lower serum testosterone levels are associated with the future development of RA, especially in patients who are rheumatoid factor-negative [15]. In SKG mouse models, testosterone inhibits the development of arthritis, indicating an inhibitory role of testosterone in the development of RA in male patients [16]. However, serum testosterone levels in AS patients are significantly higher than those in RA patients but not different from the healthy population [17]. Therefore, considering the male predominance of AS and the non-reduced testosterone levels in AS patients, testosterone might be more involved in the pathogenesis of AS compared with other types of arthritis.

Dutasteride, a 5- $\alpha$ reductase (SRD5A) inhibitor that blocks the conversion of testosterone to dihydrotestosterone (DHT), has been clinically used for the treatment of aggressive prostate cancer and alopecia [18, 19]. Although dutasteride has been proven safe, the effects of decreased DHT levels in male AS patients undergoing long-term dutasteride treatment are unknown. In the present study, the effects of dutasteride on spinal ankylosis were examined in a spondyloarthritis animal model. Furthermore, the role of DHT in the differentiation of human osteoblasts was evaluated using primary AS osteoprogenitors.

\section{Materials and methods In vivo AS model}

SKG mice were obtained from Dr. Sakaguchi (University of Osaka, Japan), and arthritis was induced as previously described [11-13]. Eight-week-old male SKG mice were intraperitoneally injected with $3 \mathrm{mg}$ of curdlan $(n=20)$ or PBS only as a control $(n=6)$ at 0 and 2 weeks. Dutasteride (SML1221, Sigma, USA), a 5- $\alpha$ reductase inhibitor that blocks the conversion of testosterone to DHT, was used for in vivo experiments. An experimental diet containing dutasteride $(41.2 \mathrm{mg} / \mathrm{kg} /$ day $)$ was started at 9 weeks after the first curdlan injection (dutasteride group, $n=10$ ) in half of the mice, and a normal diet was maintained in the remaining mice (curdlan group, $n=10$ ). The clinical scores for peripheral arthritis were evaluated weekly. At 17 weeks after the first curdlan injection, whole-body imaging was performed using the fluorescent in vivo bisphosphonate agent OsteoSense 680 EX (Mediso Ltd., Hungary). The mice were then sacrificed, and sera and splenocytes were simultaneously collected. The levels of bone metabolism-related molecules including receptor activator of nuclear factor kappa-B ligand (RANKL), osteoprotegerin (OPG), dickkopf-related protein 1 (DKK1), and sclerostin (SOST) were analyzed using a Luminex multiplex assay, and IL17A was measured using single molecule arrays. IL-17A secretory cells in the spleen were measured using flow cytometry. All mice were handled in accordance with the guidelines for animal care approved by the Animal Experimentation Committee of the Asan Institute for Life Science (2015-14-135).

\section{In vitro studies and sera analysis}

Studies involving human materials were performed in compliance with the Helsinki Declaration and approved by the Ethics Committee of Hanyang University Hospital; written informed consent was obtained from all subjects (IRB-2014-05-002). Human bone tissues were obtained during surgery from the facet joints of 12 patients who fulfilled the 1984 modified New York classification criteria for AS. Primary AS osteoprogenitor cells were cultured as previously reported $[10,20,21]$. The effects of DHT (D073, Sigma, USA) on primary AS osteoprogenitors were assessed by alkaline phosphatase (ALP) activity and staining, alizarin red staining (ARS) for calcium deposits, and qRT-PCR for osteoblasts-related genes [22]. RNA extraction (TRIzol, Thermo Fisher Scientific, USA) and cDNA synthesis (ReversAid, Thermo Fisher Scientific, USA) were performed following the standard protocols.

The qRT-PCR primers used were as follows: 18s RNA forward, 5'-GTAACCCGTTGAACCCCATTC-3'; 18s RNA reverse, 5'-CCATCCAATCGGTAGTAGCG-3'; ALP forward, 5' -ACGAGCTGAACAGGAACAACGT-3'; ALP reverse, 5'-CACCAGCAAGAAGAAGCCTTTG-3'; 
OCN forward, 5'-ATGAGAGCCCTCACACTCCT-3'; OCN reverse, 5'-CTTGGACACAAAGGCTGCAC-3'; DKK1 forward, 5'-GGGTCTTTGTCGCGATGGTA-3'; DKK1 reverse, 5' - CTGGTACTTATTCCCGCCCG-3'; SOST1 forward, 5'-TGGCAGGCGTTCAAGAATGA-3'; SOST1 reverse, 5' -GCCCGGTTCATGGTCTTGTT-3'.

Sera were collected from male subjects: 28 healthy donors (HC), 189 with AS, and 23 with RA. The DHT levels in the sera were analyzed using ELISA (KA1886, Abnova, Taiwan). Spinal radiographs of the AS patients were scored based on the modified Stoke Ankylosing Spondylitis Spinal Score (mSASSS) (Lee S).

\section{Statistical analysis}

Statistical analyses were performed using GraphPad Prism software, version 6.0. The Mann-Whitney $U$ test was performed for two-group comparisons, and $P$ values $<0.05$ were considered statistically significant. All results are presented as the mean \pm standard error of the mean (SEM). Statistical Package for Social Science (SPSS) software was used for statistical analysis. Spearman's correlation was used to determine the correlation between DHT and mSASSS.

\section{Results}

Curdlan-administered SKG mice were examined to determine the effects of dutasteride on the induction of arthritis and spinal progression in AS. The experimental design is shown in Fig. 1a. After starting the dutasteride diet, the clinical arthritis scores were not different between the dutasteride and curdlan groups (Fig. 1b). At 2 weeks before sacrifice, the accumulation of hydroxyapatite in the spinal region, which reflects osteoblast activity, was significantly increased in the dutasteride group compared with the curdlan group (Fig. 1c). The osteoblast activity was positively correlated with the IL-17A serum level (Fig. 1d). In the analysis of bone metabolism-related molecules, the OPG levels were increased in the curdlan group compared with PBStreated SKG mice but were not different between the curdlan and dutasteride groups. However, the SOST levels were markedly decreased in the dutasteride group compared with the curdlan group (Fig. 1e). Among splenocytes, the population of IL-17A secretory cells was increased in all curdlan-administered mice, with larger increases in the dutasteride group compared with the curdlan group. However, the amount of $\mathrm{T}_{\mathrm{H}} 17$ cells and IL-17A ${ }^{+}$Treg cells were not significantly different between the dutasteride and curdlan groups (Fig. 1f). Collectively, these results indicate that treatment with dutasteride does not attenuate arthritis but does increase mineralization of the spine in curdlanadministered SKG mice, likely via the IL-17A pathway.

Based on the in vivo results with dutasteride treatment as a DHT inhibitor, the effects of DHT on AS osteoprogenitor cells during osteogenic differentiation were investigated. AS osteoprogenitors exposed to DHT during osteoblast differentiation showed no differences in intercellular ALP activity or ALP staining (Fig. 2a); however, calcium deposits were decreased based on ARS staining and quantification (Fig. 2b). In addition, osteoprogenitor cells in disease controls did not differ in osteogenic activities and calcium deposits after treatment with DHT (Supplementary Figure). Accordingly, the osteocalcin $(O C N)$ expression was decreased, and DKK1 and SOST expression was increased at the mRNA level in DHTtreated AS progenitor cells (Fig. 2c).

DHT level in AS patients was significantly higher than that in other groups (Fig. 3a). However, DHT level was not correlated with radiographic progression measured based on mSASSS (Fig. 3b).

\section{Discussion}

In the present study, dutasteride treatment resulted in severe spinal ankylosis in curdlan-administered SKG mice with increased population of IL-17A-secreting cells. In a recent report, IL-17A levels and $\mathrm{T}_{\mathrm{H}} 17$ frequency were significantly higher in male AS patients than in female AS patients [9]; however, testosterone concentration was negatively associated with activation of the $\mathrm{T}_{\mathrm{H}} 17 / \mathrm{IL}-17$ axis $[23,24]$. If testosterone is increased to compensate for the activity of the $\mathrm{T}_{\mathrm{H}} 17 / \mathrm{IL}-17$ axis, suppression of testosterone might cause unexpected effects on the activation of the $\mathrm{T}_{\mathrm{H}} 17 / \mathrm{IL}-17$ axis. In the present study, an active metabolite converted from testosterone, DHT, was iatrogenically suppressed by dutasteride resulting in increased spinal mineralization in curdlanadministered SKG mice, mimicking spondyloarthritis. The intensity of mineralization was positively correlated with serum IL-17A levels, and dutasteride increased the number of viable IL-17A-secreting cells in curdlanadministered SKG mice, indicating dutasteride treatment in the in vivo model may exacerbate the pathogenic features of AS characterized by increased IL-17A and accumulation of spinal mineralization.

Clinically, anti-IL-17A antibodies are more effective for controlling the radiographic progression of AS compared with anti-TNF antibodies over a 2-year period [25], and evidence indicates IL-17A induces osteoblast differentiation from progenitor cells of AS patients [10]. The SKG mouse model is dependent on $\mathrm{T}_{\mathrm{H}} 17 / \mathrm{IL}-17$-inducible axial spondyloarthritis [12]. In the present study, dutasteride increased the proportion of viable IL-17A-secreting cells in a mouse model; however, the population of $\mathrm{T}_{\mathrm{H}} 17$ cells was not increased in the dutasteride group compared with the curdlan group. Because the cellular sources of IL-17A are lymphocytes, including $\mathrm{CD}_{4}^{+}, \mathrm{CD}^{+}, \gamma \delta$-T, invariant NKT, innate lymphoid cells, and non-T cells including neutrophils [26], the increased levels of IL-17A secretory cells caused by dutasteride might not be dependent on $\mathrm{T}_{\mathrm{H}} 17$ cells. However, whether the increased population of these cells resulted only 


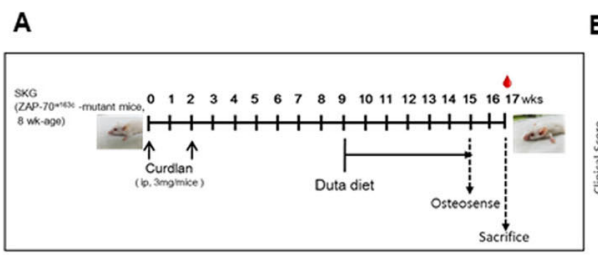

C

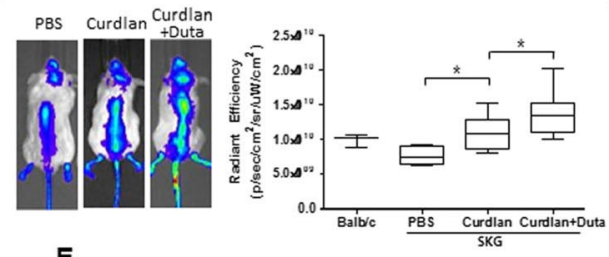

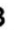

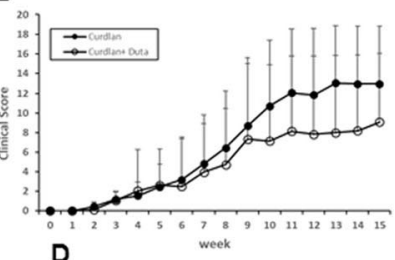

D

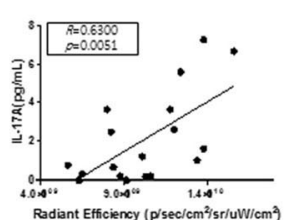

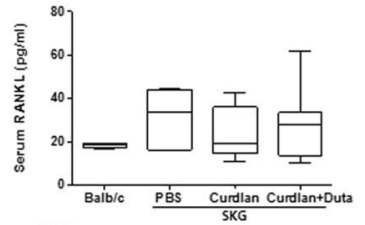
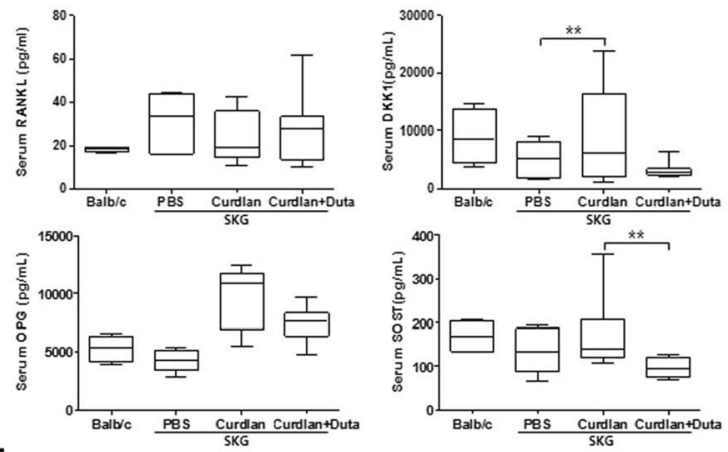

F
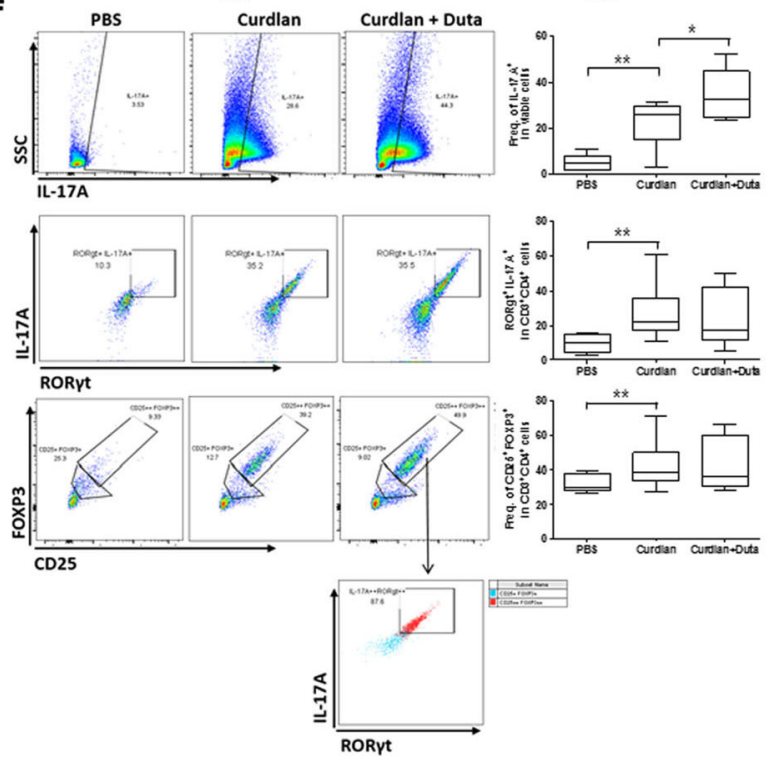

Fig. 1 Effects of dutasteride on curdlan-administered SKG mouse model. a Experimental design. b Clinical arthritis scoring. c In vivo imaging after injection of OsteoSense ${ }^{\circledR} 680$ EX probe and quantitative analysis of fluorescence values. $\mathbf{d}$ Correlation between serum IL-17A and bone mineralization. e Serum levels of bone metabolism-related molecules. $\mathbf{f}$ Flow cytometry plots showing the proportion of IL-17A cells, IL$17^{+}$RORYT cells $\left(T_{H} 17\right)$, and CD25 ${ }^{+}$FoxP3 $^{+}$cells (Treg) among splenocytes. ${ }^{*} p<0.05,{ }^{* *} p<0.01$

from the effects of dutasteride could not be determined. Regarding osteoblasts, deleterious effects of anti-IL-17A on bone mass could be a concern although the effects of IL-17A on osteoporosis in the SKG mouse model were unclear. However, IL-17A is also a potent activator of osteoclast differentiation $[27,28]$, which triggers osteoporosis.
Primary bone-derived cells from the facet joints of AS patients were used to examine the effects of DHT and dutasteride in vitro. Dutasteride treatment did not show any significant changes in AS osteoprogenitor cells under osteogenic differentiation conditions (data not shown). However, a significant reduction of calcified nodules was 


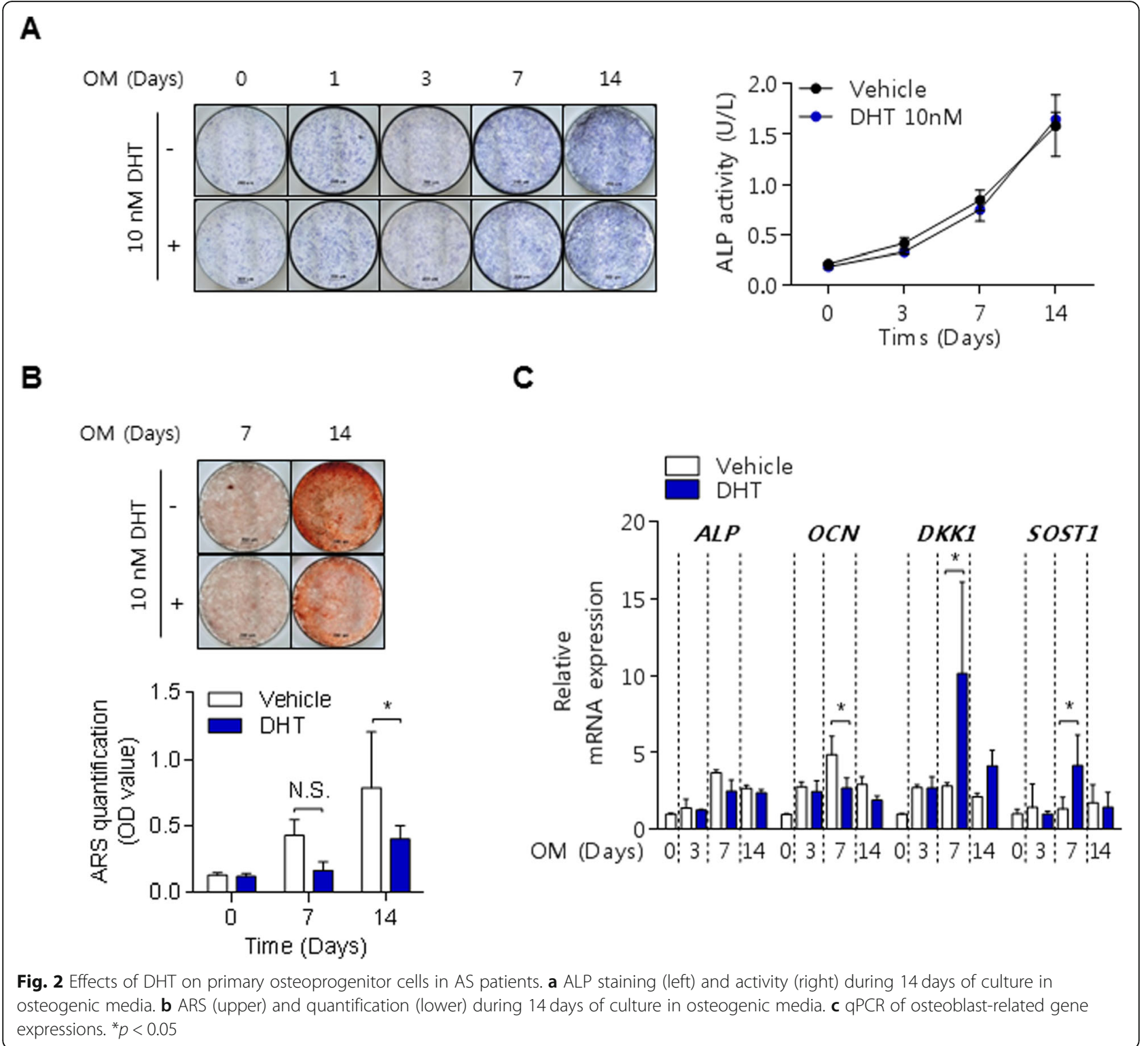

A

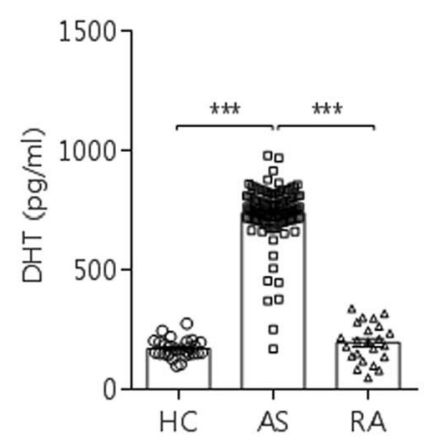

B

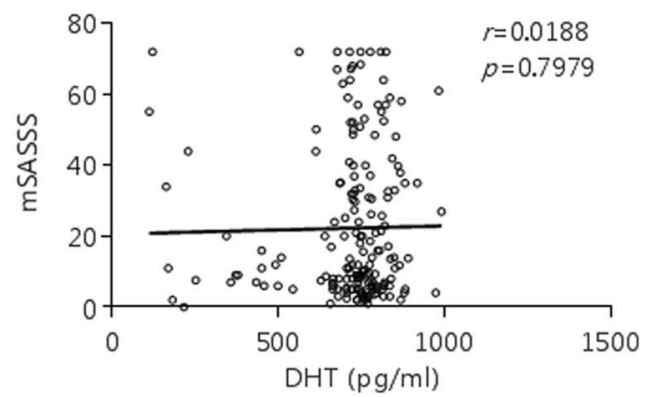

Fig. 3 DHT level and mSASSS in patients with AS. a DHT levels in HC $(n=28)$, AS $(n=189)$, and RA patients $(n=23)$. b The lack of correlation of DHT levels with mSASSS in AS patients 
observed under osteogenic conditions stimulated with DHT, although ALP activity was not different, as shown in Fig. 2. DHT treatment for 7 days under osteogenic conditions markedly increased the mRNA expression of $D K K 1$ and SOST and decreased OCN expression. Therefore, DHT treatment in AS osteoprogenitor cells delayed the physiological changes of osteogenic differentiation by activating DKK1 and SOST expression. DHT was higher in the serum of AS patients than in RA patients or healthy controls; however, cross-sectional DHT levels were not correlated with mSASSS (Fig. 3b). In agreement with the results from the present study, the testosterone level did not correlate with mSASSS scores in male AS patients [29]. Therefore, the association of male hormone levels with mSASSS should be investigated in a serial follow-up or a large retrospective study.

The role of DKK1 or SOST in bone biology as potent antagonists of the Wnt signaling pathway has been previously reported [30]. Specifically, secreted DKK1 and SOST negatively regulate the LRP5/6 receptors of osteoblasts and inhibit Wnt-mediated bone formation by acting at several differentiation stages of the osteoblasts. Transgenic SOST-knockout mice display a high bone mass with increased bone mineralization [31, 32]. In several clinical studies, serum SOST levels were reduced in AS patients, and SOST has been proposed as a marker of radiographic progression. Furthermore, SOST levels were increased by treatment with an anti-TNF inhibitor [33]. Taken together, these data indicate the increased bone formation in the spinal region of mice in the current study could be due to reduced serum SOST levels caused by dutasteride treatment.

Several AS patients experience hair loss, for which dutasteride could be prescribed concomitantly. Despite the clinical relevance, the effects of dutasteride on the disease progression of patients with AS have not been determined in previous studies. In the present study, the possible harmful effects of dutasteride on bone formation in AS were presented. The experimental dutasteride diet in representative male SKG mice was designed to mimic human AS disease in vivo. The increased number of IL17A-secreting cells and IL-17A cytokine levels and decreased SOST levels in response to dutasteride are largely consistent with the pathogenic factors associated with AS.

The present study had several limitations. First, the precise mechanism by which IL-17A-secreting cells and IL-17 cytokines were increased by dutasteride could not be determined. Second, the mechanism of androgen receptor-regulation mediated by DHT in primary cells was not clearly defined; thus, further research is needed to better understand the underlying actions of regulatory male hormones. In addition, clinical studies are needed to verify the effects on the spinal structure in AS patients undergoing dutasteride therapy for prostate cancer. Third, the AS osteoprogenitors investigated in the present study might be inappropriate to explain the complete mechanism of syndesmophyte formation; however, the focus was on osteoblast proliferation, which was the reason for choosing the particular AS osteoprogenitors. Finally, an alternative mechanism of severe ankylosis caused by dutasteride, such as microbiota, was not fully evaluated. Imbalance of gut microbiota was suggested as a possible pathogenesis in a HLA-B27-induced spondyloarthritis model [34]. In addition, a sex-related distinct population of microbiota during development of inflammatory bowel diseases has recently been reported [35]. Therefore, effects of dutasteride on the imbalance of microbiota should be studied in the future.

\section{Conclusion}

Treatment with a DHT inhibitor in curdlan-administered SKG mice led to increased mineralization of the spine in vivo, and DHT treatment attenuated osteoblast differentiation in vitro. Therefore, the prescription of regimens inhibiting DHT in AS patients warrants careful consideration regarding the progression of spinal ankylosis.

\section{Abbreviations \\ AS: Ankylosing spondylitis; HC: Healthy control; RA: Rheumatoid arthritis; mSASSS: Modified Stoke Ankylosing Spondylitis Spinal Score; \\ DHT: Dihydrotestosterone; ALP: Alkaline phosphatase; ARS: Alizarin red staining; IL-17A: Interleukin-17A; DKK1: Dickkopf-related protein 1; \\ SOST: Sclerostin; OCN: Osteocalcin; OPG: Osteoprotegerin; RANKL: Receptor activator of nuclear factor kappa $\mathrm{B}$ ligand}

\section{Acknowledgements}

We would like to thank all the patients and healthy control subjects who participated in this study. We would like to thank the Optical Imaging core facility at the ConveRgence mEDIcine research center (CREDIT) at Asan Medical Center for technical support. We truly appreciate Dr. Sang-Cheol Bae (Hanyang University Hospital for Rheumatic Disease) for providing the sera of male RA patients.

\section{Authors' contributions}

SJ and E-JL performed all experimental design and data analysis. SJ, E-JL, YGK, and THK participated in writing the manuscript. BN, JK, and SL analyzed the clinical disease scores of patients. JY and Y-SP provided SKG mice and human facet joint samples, respectively. Y-GK and T-HK conceived of the overall concept and guided the study. All authors read the manuscript critically, provided comments, and approved the final version.

\section{Funding}

This research was supported by grants from the Basic Science Research Program through the National Research Foundation of Korea (NRF) funded by the Ministry of Education (2017R1A6A3A11034394 to SJ, 2019R1F1A1059736 to Y-GK, and 2016R1A2B4008606 and

2019R1A2C2004214 to T-HK). It was also supported by a Korea Health Technology R\&D grant through the Korea Health Industry Development Institute (KHIDI), which is funded by the Ministry of Health \& Welfare, Republic of Korea (HI17C0888 to T-HK).

\section{Availability of data and materials}

All data generated and analyzed during this study are included in this article. Materials used in this study are available from the corresponding author on reasonable request.

\section{Ethics approval and consent to participate}

Studies involving human materials were carried out in compliance with the Helsinki Declaration and were approved by the Ethics Committee of

Hanyang University Hospital with written informed consent from all subjects 
(IRB-2014-05-002). All mice were handled in accordance with the guidelines for animal care approved by the Animal Experimentation Committee of the Asan Institute for Life Science (2015-14-135).

\section{Consent for publication}

Not applicable.

\section{Competing interests}

All authors declare no conflict of interest.

\section{Author details}

${ }^{1}$ Hanyang University Institute for Rheumatology Research, Seoul, Republic of Korea. ${ }^{2}$ Division of Rheumatology, Department of Medicine, University of Ulsan College of Medicine, Asan Medical Center, Seoul, Republic of Korea. ${ }^{3}$ Department of Rheumatology, Hanyang University Hospital for Rheumatic Diseases, Seoul, Republic of Korea. ${ }^{4}$ Department of Radiology, Hanyang University Hospital, Seoul, Republic of Korea. ${ }^{5}$ Department of Anatomy and Cell Biology, College of Medicine, Hanyang University, Seoul, Republic of Korea. ${ }^{6}$ Department of Orthopedic Surgery, Hanyang University Guri Hospital, Guri, Republic of Korea.

Received: 15 October 2019 Accepted: 12 May 2020

Published online: 24 May 2020

\section{References}

1. Lee W, Reveille JD, Davis JC Jr, Learch TJ, Ward MM, Weisman MH. Are there gender differences in severity of ankylosing spondylitis? Results from the PSOAS cohort. Ann Rheum Dis. 2007:66(5):633-8.

2. Deminger A, Klingberg E, Geijer M, Gothlin J, Hedberg M, Rehnberg E, Carlsten $\mathrm{H}$, Jacobsson LT, Forsblad-d'Elia $\mathrm{H}$. A five-year prospective study of spinal radiographic progression and its predictors in men and women with ankylosing spondylitis. Arthritis Res Ther. 2018;20(1):162.

3. Straub RH, Struharova S, Scholmerich J, Harle P. No alterations of serum levels of adrenal and gonadal hormones in patients with ankylosing spondylitis. Clin Exp Rheumatol. 2002;20(6 Suppl 28):S52-9.

4. Mitra D, Elvins DM, Collins AJ. Testosterone and testosterone free index in mild ankylosing spondylitis: relationship with bone mineral density and vertebral fractures. J Rheumatol. 1999;26(11):2414-7.

5. Giltay EJ, Popp-Snijders C, van Schaardenburg D, Dekker-Saeys BJ, Gooren $\sqcup$, Dijkmans BA. Serum testosterone levels are not elevated in patients with ankylosing spondylitis. J Rheumatol. 1998;25(12):2389-94.

6. Liu CH, Raj S, Chen $\mathrm{CH}$, Hung KH, Chou CT, Chen IH, Chien JT, Lin IY, Yang SY, Angata T, et al. HLA-B27-mediated activation of TNAP phosphatase promotes pathogenic syndesmophyte formation in ankylosing spondylitis. J Clin Invest. 2019;129(12):5357-73.

7. Zhu W, He X, Cheng K, Zhang L, Chen D, Wang X, Qiu G, Cao X, Weng X Ankylosing spondylitis: etiology, pathogenesis, and treatments. Bone Res. 2019;7:22.

8. Ellinghaus D, Jostins L, Spain SL, Cortes A, Bethune J, Han B, Park YR Raychaudhuri S, Pouget JG, Hubenthal M, et al. Analysis of five chronic inflammatory diseases identifies 27 new associations and highlights diseasespecific patterns at shared loci. Nat Genet. 2016;48(5):510-8.

9. Gracey E, Yao Y, Green B, Qaiyum Z, Baglaenko Y, Lin A, Anton A, Ayearst R, Yip P, Inman RD. Sexual dimorphism in the Th17 signature of ankylosing spondylitis. Arthritis Rheumatol. 2016;68(3):679-89.

10. Jo S, Wang SE, Lee YL, Kang S, Lee B, Han J, Sung IH, Park YS, Bae SC, Kim TH. IL-17A induces osteoblast differentiation by activating JAK2/STAT3 in ankylosing spondylitis. Arthritis Res Ther. 2018;20(1):115.

11. Sakaguchi N, Takahashi T, Hata H, Nomura T, Tagami T, Yamazaki S, Sakihama T, Matsutani T, Negishi I, Nakatsuru S, et al. Altered thymic T-cell selection due to a mutation of the ZAP-70 gene causes autoimmune arthritis in mice. Nature. 2003;426(6965):454-60.

12. Benham H, Rehaume LM, Hasnain SZ, Velasco J, Baillet AC, Ruutu M, Kikly K, Wang R, Tseng HW, Thomas GP, et al. Interleukin-23 mediates the intestinal response to microbial beta-1,3-glucan and the development of spondyloarthritis pathology in SKG mice. Arthritis Rheumatol. 2014;66(7):1755-67.

13. Kwon OC, Lee EJ, Chang EJ, Youn J, Ghang B, Hong S, Lee CK, Yoo B, Kim YG. IL-17A(+)GM-CSF(+) neutrophils are the major infiltrating cells in interstitial lung disease in an autoimmune arthritis model. Front Immunol. 2018;9:1544.

14. Lim DH, Lee EJ, Kwon OC, Hong S, Lee CK, Yoo B, Youn J, Kim TH, Kim YG. Effect of tumor necrosis factor inhibition on spinal inflammation and spinal ankylosis in SKG mice. Sci Rep. 2019;9(1):18000.
15. Pikwer M, Giwercman A, Bergstrom U, Nilsson JA, Jacobsson LT, Turesson C. Association between testosterone levels and risk of future rheumatoid arthritis in men: a population-based case-control study. Ann Rheum Dis. 2014;73(3):573-9.

16. Keith RC, Sokolove J, Edelman BL, Lahey L, Redente EF, Holers VM, Sakaguchi S, Robinson $\mathrm{WH}$, Riches DW. Testosterone is protective in the sexually dimorphic development of arthritis and lung disease in SKG mice. Arthritis Rheum. 2013,65(6):1487-93.

17. Spector TD, Ollier W, Perry LA, Silman A, Thompson PW, Edwards A. Free and serum testosterone levels in 276 males: a comparative study of rheumatoid arthritis, ankylosing spondylitis and healthy controls. Clin Rheumatol. 1989;8(1):37-41.

18. Bhasin S, Travison TG, Storer TW, Lakshman K, Kaushik M, Mazer NA, Ngyuen AH, Davda MN, Jara H, Aakil A, et al. Effect of testosterone supplementation with and without a dual 5alpha-reductase inhibitor on fat-free mass in men with suppressed testosterone production: a randomized controlled trial. JAMA. 2012;307(9):931-9.

19. Andriole GL, Bostwick DG, Brawley OW, Gomella LG, Marberger M, Montorsi F, Pettaway CA, Tammela TL, Teloken C, Tindall DJ, et al. Effect of dutasteride on the risk of prostate cancer. N Engl J Med. 2010;362(13):1192-202.

20. Jo S, Kang S, Han J, Choi SH, Park YS, Sung IH, Kim TH. Accelerated osteogenic differentiation of human bone-derived cells in ankylosing spondylitis. J Bone Miner Metab. 2018;36(3):307-13.

21. Jo S, Han J, Lee YL, Yoon S, Lee J, Wang SE, Kim TH. Regulation of osteoblasts by alkaline phosphatase in ankylosing spondylitis. Int J Rheum Dis. 2019:22(2):252-61.

22. Jo S, Yoon S, Lee SY, Kim SY, Park H, Han J, Choi SH, Han JS, Yang JH, Kim TH. DKK1 induced by 1,25D3 is required for the mineralization of osteoblasts. Cells. 2020;9(1)

23. Fuseini $H$, Yung JA, Cephus JY, Zhang J, Goleniewska K, Polosukhin W, Peebles RS Jr, Newcomb DC. Testosterone decreases house dust mite-induced type 2 and IL-17A-mediated airway inflammation. J Immunol. 2018;201(7):1843-54.

24. Schwinge D, Carambia A, Quaas A, Krech T, Wegscheid C, Tiegs G, Prinz I, Lohse AW, Herkel J, Schramm C. Testosterone suppresses hepatic inflammation by the downregulation of IL-17, CXCL-9, and CXCL-10 in a mouse model of experimental acute cholangitis. J Immunol. 2015;194(6):2522-30.

25. Braun J, Baraliakos X, Deodhar A, Baeten D, Sieper J, Emery P, Readie A, Martin R, Mpofu S, Richards HB, et al. Effect of secukinumab on clinical and radiographic outcomes in ankylosing spondylitis: 2-year results from the randomised phase III MEASURE 1 study. Ann Rheum Dis. 2017;76(6):1070-7.

26. Cua DJ, Tato CM. Innate IL-17-producing cells: the sentinels of the immune system. Nat Rev Immunol. 2010;10(7):479-89.

27. Yago T, Nanke Y, Ichikawa N, Kobashigawa T, Mogi M, Kamatani N, Kotake S. IL17 induces osteoclastogenesis from human monocytes alone in the absence of osteoblasts, which is potently inhibited by anti-TNF-alpha antibody: a novel mechanism of osteoclastogenesis by IL-17. J Cell Biochem. 2009:108(4):947-55.

28. Adamopoulos IE, Chao CC, Geissler R, Laface D, Blumenschein W, Iwakura Y, McClanahan T, Bowman EP. Interleukin-17A upregulates receptor activator of NF-kappaB on osteoclast precursors. Arthritis Res Ther. 2010;12(1):R29.

29. Odeh S, Odeh M, Slobodin G, Shechner C, Saiegh L. Spinal syndesmophyte score does not correlate with serum testosterone level in male patients with ankylosing spondylitis. Harefuah. 2019;158(9):568-70.

30. Baron R, Rawadi G. Targeting the Wnt/beta-catenin pathway to regulate bone formation in the adult skeleton. Endocrinology. 2007;148(6):2635-43.

31. Li X, Ominsky MS, Niu OT, Sun N, Daugherty B, D'Agostin D, Kurahara C, Gao Y, Cao J, Gong J, et al. Targeted deletion of the sclerostin gene in mice results in increased bone formation and bone strength. J Bone Miner Res. 2008;23(6):860-9.

32. Lories RJ, Haroon N. Bone formation in axial spondyloarthritis. Best Pract Res Clin Rheumatol. 2014;28(5):765-77.

33. Saad CG, Ribeiro AC, Moraes JC, Takayama L, Goncalves CR, Rodrigues MB, de Oliveira RM, Silva CA, Bonfa E, Pereira RM. Low sclerostin levels: a predictive marker of persistent inflammation in ankylosing spondylitis during anti-tumor necrosis factor therapy? Arthritis Res Ther. 2012;14(5):R216.

34. Gill T, Brooks SR, Rosenbaum JT, Asquith M, Colbert RA. Novel inter-omic analysis reveals relationships between diverse gut microbiota and host immune dysregulation in HLA-B27-induced experimental spondyloarthritis. Arthritis Rheumatol. 2019:71(11):1849-57.

35. Son HJ, Kim N, Song CH, Nam RH, Choi SI, Kim JS, Lee DH. Sex-related alterations of gut microbiota in the C57BL/6 mouse model of inflammatory bowel disease. J Cancer Prev. 2019;24(3):173-82.

\section{Publisher's Note}

Springer Nature remains neutral with regard to jurisdictional claims in published maps and institutional affiliations. 